\section{Does Metastatic Lymph Node Ratio Really Suit for Prognostic Prediction of the D1 Lymphadenectomy?}

\section{TO THE EDITORS:}

Recently, Maduekwe et al. reported the results of their retrospective clinical study of the best prognostic prediction of metastatic lymph node ratio in gastric cancer patients who underwent the D1 lymphadenectomy. ${ }^{1}$

Although the results are the novel and original in the reports from the United States, we think there are some detailed matters should be further discussed in that study. First, the enrolled patients in that study included cases with positive resection margin, lymphovascular invasion, and venous invasion, which should be considered as noncurative resection and potentially distant metastasis for patients according to the AJCC/UICC or JGCA. Therefore, the 5-year survival rate must be influenced inevitably.

Furthermore, patients with no fewer than 15 dissected nodes had significantly higher $\mathrm{T}$ stage, $\mathrm{N}$ stage, $\mathrm{Nr}$ stage, and TNM stage than those with fewer than 15 dissected nodes. Obviously, most of the patients with no fewer than 15 dissected nodes were in the advanced stage of disease, which must incur the markedly dismal survival result in these patients, compared with those patients with fewer than 15 dissected nodes. Besides, the tumor size that is reported as an important prognostic independent factor of gastric cancer after curative resection in many articles of patients with no fewer than 15 dissected nodes was much bigger than that of patients with fewer than 15 dissected nodes. ${ }^{2,3}$ Therefore, we think the conclusion of that study of "Based on the factors which were significantly different between patients with $<15$ and $\geq 15$ nodes examined, the patients with $\geq 15$ nodes were generally a poorer prognosis group" is not very accurate.

Last, we could not understand why the author designed the $\mathrm{NrO}$ as the patients with no regional lymph node metastases who also had $\geq 15$ lymph nodes examined, while the patients with no regional lymph node metastases who had $<15$ lymph nodes examined were included in the Nr1 group. Actually, all enrolled patients underwent the D1 lymphadenectomy that could not provide the extragastric lymph node metastatic information in spite of the number of dissected nodes. The stage migration of lymph node metastasis is inevitable for all patients, even in patients with no fewer than 15 dissected nodes who presented without positive nodes. In our previous study, we demonstrated that patients with no fewer than 15 dissected nodes who presented with positive nodes had significantly higher 5-year survival rate than those with fewer than 15 dissected nodes who presented with positive nodes using the casecontrol method analysis. ${ }^{4}$ So we suggest that author may analyze the difference of survival rates between the patients with no fewer than 15 dissected nodes and the patients with fewer than 15 dissected nodes with detailed stratified analysis.

\section{Jingyu Deng, MD, and Han Liang, MD}

Gastric Cancer Surgery Division, Tianjin Medical University Cancer Hospital and City Key Laboratory of Tianjin Cancer Center, Tianjin, China

e-mail: dengery@sohu.com

Published Online: 16 April 2010

(C) Society of Surgical Oncology 2010

\section{REFERENCES}

1. Maduekwe UN, MD, Lauwers GY, Fernandez-del-Castillo C, Berger DL, Ferguson CM, Rattner DW, et al. New metastatic lymph node ratio system reduces stage migration in patients undergoing D1 lymphadenectomy for gastric adenocarcinoma. Ann Surg Oncol. 2010 Jan 23. [Epub ahead of print]. doi:10.1245/ s10434-010-0914-6.

2. Jun KH, Jung H, Baek JM, Chin HM, Park WB. Does tumor size have an impact on gastric cancer? A single institute experience. Langenbecks Arch Surg. 2009;394:631-5.

3. Liu X, Xu Y, Long Z, Zhu H, Wang Y. Prognostic significance of tumor size in T3 gastric cancer. Ann Surg Oncol. 2009;16:187582.

4. Deng JY, Liang H, Sun D, Pan Y, Zhang RP, Wang BG, et al. Outcome in relation to numbers of nodes harvested in lymph node positive gastric cancer. Euro J Surg Oncol. 2009;35:814-9. 